\title{
An investigation of the Formability Behaviour of High Strength Aluminium Alloys Using Different Heat Assisted Forming Processes
}

\author{
M. Schmiedt ${ }^{\mathrm{a}, \mathrm{b}, 1}$, J. M. Schlosser ${ }^{\mathrm{a}}$, R. Schneider ${ }^{\mathrm{c}}$, W. Rimkus ${ }^{\mathrm{a}}$, D. K. Harrison ${ }^{\mathrm{b}}$ \\ ${ }^{a}$ Lightweight Construction Center, University Aalen, Beethovenstr.1, 73430 Aalen, \\ Germany \\ ${ }^{b}$ Department of Engineering and Built Environment, Glasgow Caledonian University, \\ Cowcaddens Road, Glasgow, United Kingdom \\ ${ }^{c}$ Department of Mechatronics and Medical Engineering, University of Applied \\ Sciences Ulm, Albert-Einstein-Allee 55, 89081 Ulm, Germany
}

\begin{abstract}
The usage of ultra-high strength aluminium alloys (EN AW-7000 series) offers a great weight saving potential due to the high rigidity and specific strength values. Various heat assisted forming technologies have been developed in order to improve the limited formability at room temperature and thus to be able to increase the geometrical complexity of such sheet metal parts. In this study the forming behaviour of EN AW-7021 sheet metal alloy is described as a function of the forming process and the corresponding temperature profile. The forming limit curves (FLCs) are obtained by experimental Nakajima tests using the Warmforming, Hotforming, extended Hotforming and W-Temper process route. For this purpose, a Nakajima testing tool is designed according to ISO 12004 standard which allows operating temperatures of up to $200^{\circ} \mathrm{C}$.
\end{abstract}

Keywords. FLC, Nakajima, high strength aluminium alloy, heat assisted forming

\section{Introduction}

Lightweight engineering and the associated weight reduction are important factors when complying with increasingly stringent emission regulations for automotive or aerospace components. Aluminium and its ultra-high strength alloys (AA7xxx) in particular are the subject of major importance due to their great weight saving potential [1]. Unfortunately, the forming behaviour of these alloys is restricted at room temperature since they lack both sufficient formability and strain hardening behaviour. With the aim of improving their formability, several heat assisted forming strategies have been investigated in recent years in order to substitute conventional cold forming processes. So far, complex shaped sheet metal components made of ultra-high strength aluminium alloys can be produced economically viable using the Warmforming [2-5], Hotforming [6-9] and W-Temper [10-12] processes.

\footnotetext{
${ }^{1}$ Corresponding Author. michael.schmiedt@hs-aalen.de
} 
Based on the Hotforming process current research focuses on modifications in order to manufacture hybrid components made out of high-strength aluminium alloys and local fibre-reinforced plastic patches. The so called "extended Hotforming" process is based on an integrated thermal direct joining step [13]. The temperature curve of each process is qualitatively shown in Figure 1.

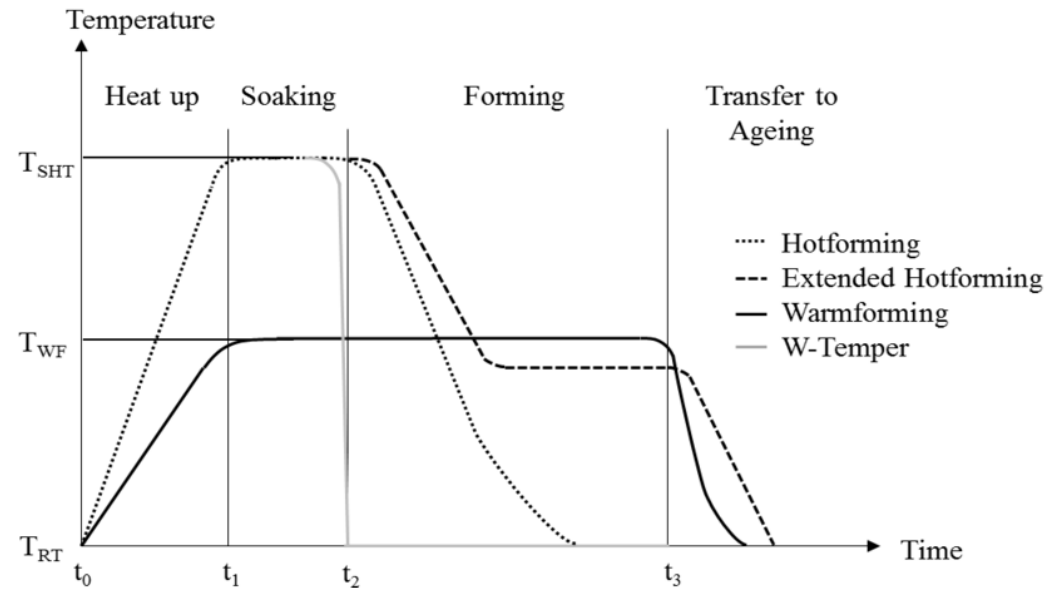

Figure 1: Qualitative temperature curves of the heat assisted forming processes $\left(\mathrm{T}_{\mathrm{SHT}}=\right.$ solution heat treatment temperature, $\mathrm{T}_{\mathrm{WF}}=$ Warmforming temperature, $\mathrm{T}_{\mathrm{RT}}=$ room temperature)

However, the forming methods indicated result in deviating values for strength and formability due to the corresponding temperature profile and material condition. Yet, a direct comparison of the forming behaviour as a function of the forming process used has not been made. For this purpose, a Nakajima testing tool was designed which allows operation temperatures of up to $200{ }^{\circ} \mathrm{C}$.

\section{Experimental methods}

In order to investigate the process influence on formability, forming limit curves (FLC) were determined according to ISO 12004 standard [14] for EN AW-7021 sheet material. A set of specimen variations were prepared with various strip-widths in order to obtain different strain states. For statistics, four experiments were conducted for each stripwidth and process. The material and test parameters used are listed in Table 1.

Table 1: Material and test parameters for Nakajima testing

\begin{tabular}{ccc}
\hline Parameter & Unit & Value \\
\hline Alloy & {$[-]$} & EN AW-7021 \\
Sheet thickness & {$[\mathrm{mm}]$} & 2 \\
Specimen strip-width & {$[\mathrm{mm}]$} & $30,80,90,110,130,250$ \\
Punch radius & {$[\mathrm{mm}]$} & 100 \\
Testing speed & {$[\mathrm{mm} / \mathrm{s}]$} & 1.7 \\
Blank holder force & {$[\mathrm{kN}]$} & 400 \\
Solution treatment & {$\left[{ }^{\circ} \mathrm{C}\right]$} & 515 \\
Forming temperature & {$\left[{ }^{\circ} \mathrm{C}\right]$} & RT, 190 \\
Lubrication & {$[-]$} & multilayer hybrid lubrication \\
\hline
\end{tabular}


The tests were carried out under process-oriented conditions in a hydraulic forming press from Rapp \& Seidt. The specimens were constrained between blank holder and die with a sufficiently high blank holder force to avoid any flow of the sheet material. The test bench (Figure 2) comprises a furnace for solution treatment, a hydraulic $1200 \mathrm{kN}$ press (1), a heatable Nakajima testing tool consisting of a die (2), blank holder (3) and punch (4), specimens with varying strip-widths (5) and an optical strain measurement system (GOM Aramis Adjustable) (6). The tool components can be heated separately by heating cartridges to ensure a uniform temperature distribution in the specimen.
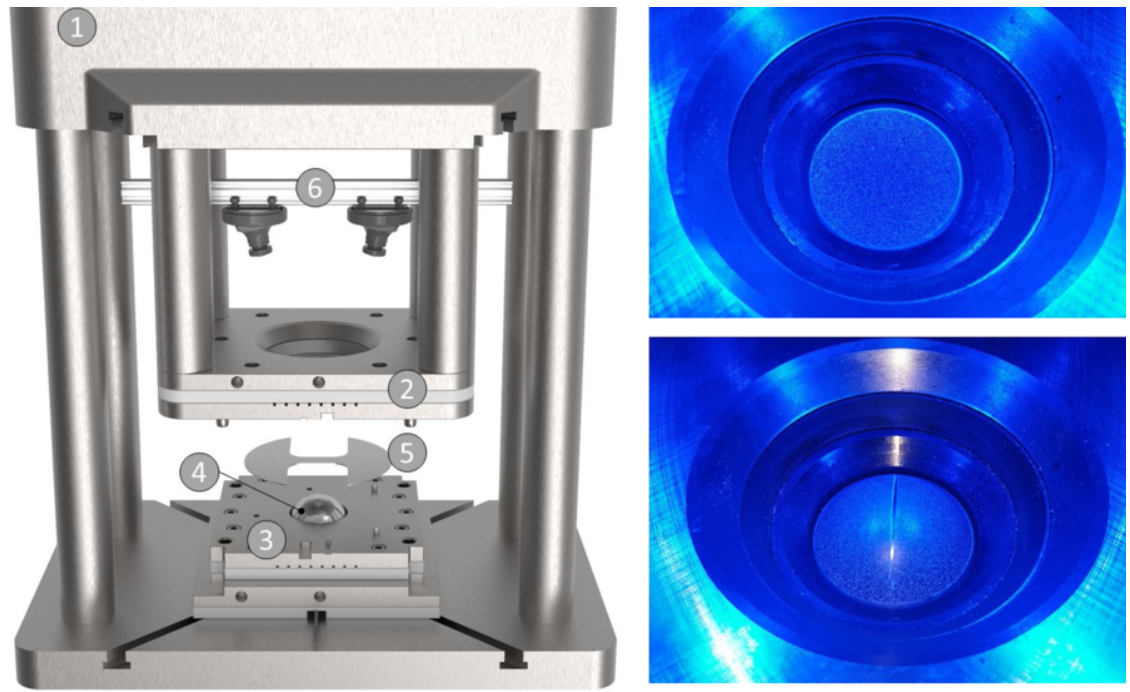

Figure 2: Nakajima test setup and crack formation in a deformed specimen

In the Hotforming process the specimens were heated up in a furnace to the solution heat treatment temperature $\left(\mathrm{T}_{\mathrm{SHT}} \approx 515^{\circ} \mathrm{C}\right)$. The temperature was maintained for a period of 3 minutes to ensure that all coarse precipitates are dissolved. Afterwards, the specimens were transferred within 7 seconds to the unheated Nakajima tool where they were formed and quenched by the cold tool components. Special attention was given to the critical cooling rate for EN AW-7021 which is approx. $10 \mathrm{~K} / \mathrm{s}$ [15]. In the W-Temper process the specimens were quenched to ambient temperature after solution annealing and formed immediately afterwards to avoid any natural ageing. The rapid cooling was achieved by a separate water bath. Using the Warmforming route, the specimens were heated up directly in the Nakajima testing tool and formed as soon as a temperature of $190{ }^{\circ} \mathrm{C}$ was reached. In contrast to Hotforming, the specimens used in the extended Hotforming process were transferred from the solution heat treatment to the heated Nakajima tool $\left(190^{\circ} \mathrm{C}\right)$ within 7 seconds. The specimens were then maintained for a period of 3 minutes within the Nakajima testing tool in order to cool the specimen from approx. $515^{\circ} \mathrm{C}\left(\mathrm{T}_{\mathrm{SHT}}\right)$ to the forming temperature of $190{ }^{\circ} \mathrm{C}$. The thermal treatment applied in each process is shown in Figure 3. Prior to any heat treatment a stochastic pattern was sprayed onto the specimen surfaces using heat-resistant paint. To reduce friction, especially at elevated temperatures, a multi-layer hybrid lubrication system was used and applied between the punch and the specimen. 


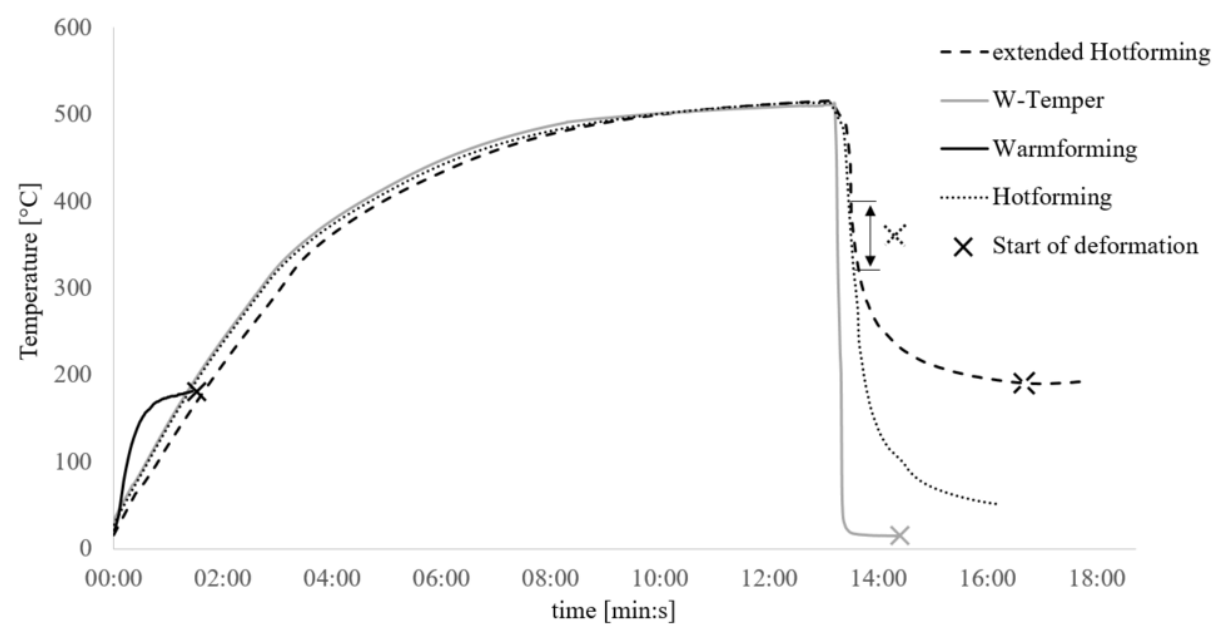

Figure 3: Temperature profiles of the various process routes used for Nakajima testing

\section{Results and discussion}

The experimental forming limit curves are shown in Figure 4. The major strain values are plotted on the ordinate and the minor strain values are indicated on the abscissa. It is noted that forming limit strains can generally be determined by different criteria: the time based or cross section based evaluation method [14]. In this study, the cross section method is used since time based or hybrid evaluation methods are not compliant with the ISO 12004 standard so far. Using the W-Temper process, the material exhibits a major strain value of 0.21 at the lowest point of the curve (close to plane strain condition) while the maximum value is 0.3 for the uniaxial tension state (Figure 4 a). Similar values are determined by applying the Hotforming process (Figure $4 \mathrm{c}$ ), where the specimens are quenched after solid solution heat treatment in the cold Nakajima testing tool. It is assumed that the same material condition for both forming processes (Hotforming and W-Temper) might be the reason for the good correlation between both FLC's. The values for major and minor strain are also consistent with the investigations of Grohmann [10], where AMAG 7021+ material was tested using the W-Temper process route. Here, the results showed a minimum major strain of approx. 0.2 and a maximum major strain of 0.28 for the uniaxial tension state. Compared to the present study the strain values for the equibiaxial tension state differ by approx. 0.05 for both major and minor deformation. The FLC determined by Grohmann is shown in Figure 4 a (black-coloured).

Using the Warmforming process the material exhibits a major strain value of approx. 0.35 at the lowest point of the curve while the maximum value is 0.47 for the uniaxial tension state (Figure $4 \mathrm{~b}$ ). The major strain values for the equibiaxial stress state indicate the same level as it can be seen for the plane strain state. Considering the FLC evaluated by the extended Hotforming process route, the tested aluminium alloy shows a major strain value of 0.28 at the lowest point and a value of 0.48 at maximum. 

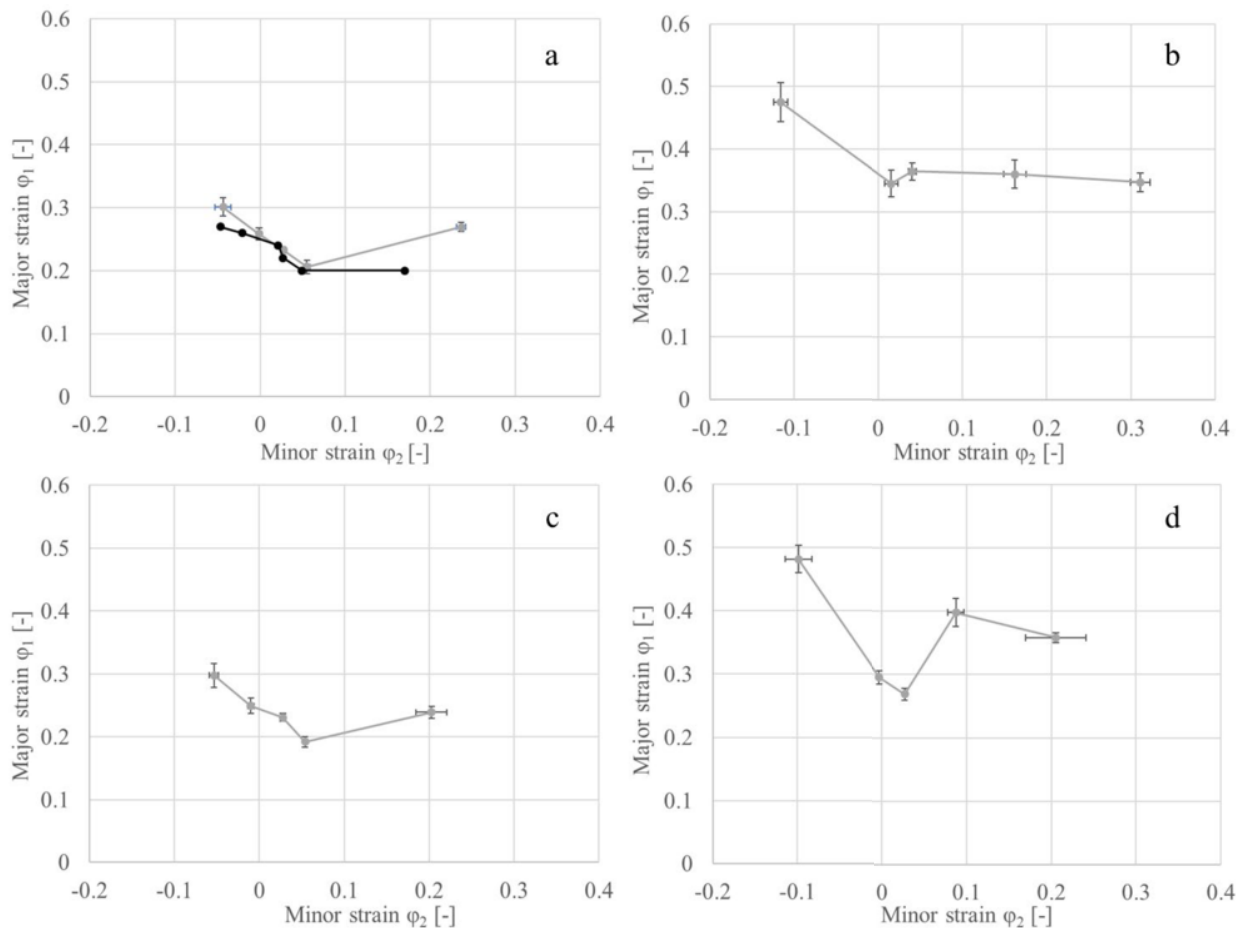

Figure 4: Experimental forming limit curves for EN AW-7021 using the a) W-Temper, b) Warmforming, c) Hotforming and d) extended Hotforming process route

The Warmforming process route was found to show both the highest major as well as minor strain values. However, the results obtained in the present study cannot be directly applied to the industrial Warmforming process since heating is usually carried out full-surface within a few seconds and in a separate unit, requiring a transfer to the heated forming tool [16]. For the Warmforming process, it is of note that the heating rate and holding time at elevated temperature have a significant influence on the strength and fracture elongation of 7xxx sheet material [17]. Polak et al. [5] demonstrated for 7075 alloy that strength decreases with increasing holding time at $200{ }^{\circ} \mathrm{C}$.

\section{Conclusions}

The formability of high-strength aluminium alloys is limited at room temperature and can be improved by heat assisted forming methods. In the present work, the highest major and minor strain values were achieved using the Warmforming process. The results need to be confirmed by tensile tests carried out at the process-specific temperature profile and numerical approaches such as CrachFEM [18] in order to counteract the influence of friction and to demonstrate the individual strength characteristics of the tested material at elevated forming temperature. In addition, the data obtained need to be supplemented by further investigations on the agreement between real components and numerical forming simulation, where the FLC's are used for failure modelling. 


\section{References}

[1] J. Schlosser, R. Schneider, W. Rimkus, R. Kelsch, F. Gerstner, D. K. Harrison and R. J. Grant, "Materials and simulation modelling of a crash-beam performance - a comparison study showing the potential for weight saving using warm-formed ultra-high strength aluminium alloys," Journal of Physics: Conference Series, vol. 896, p. 12091, 2017. DOI: https://doi.org/10.1088/17426596/896/1/012091.

[2] H. Wang, Y. Luo, P. Friedman, M. Chen and L. Gao, "Warm forming behavior of high strength aluminum alloy AA7075," Transactions of Nonferrous Metals Society of China, vol. 22, no. 1, pp. 1-7, 2012. DOI: https://doi.org/10.1016/S1003-6326(11)61131-X.

[3] K. Zheng, D. J. Politis, L. Wang and J. Lin, "A review on forming techniques for manufacturing lightweight complex - shaped aluminium panel components," International Journal of Lightweight Materials and Manufacture, vol. 1, no. 2, pp. 55-80, 2018. DOI: https://doi.org/10.1016/j.ijlmm.2018.03.006.

[4] S. Kurukuri, A. H. van den Boogaard, A. Miroux and B. Holmedal, "Warm forming simulation of Al-Mg sheet,” Journal of Materials Processing Technology, vol. 209, 15-16, pp. 5636-5645, 2009. DOI: https://doi.org/10.1016/j.jmatprotec.2009.05.024.

[5] S. Polak, P. Kaczyński, Z. Gronostajski, K. Jaskiewicz, J. Krawczyk, M. Skwarski, M. Zwierzchowski and W. Chorzępa, "Warm forming of 7075 aluminum alloys," Procedia Engineering, vol. 207, pp. 2399-2404, 2017. DOI: https://doi.org/10.1016/j.proeng.2017.10.1015.

[6] Y. Liu, Z. Zhu, Z. Wang, B. Zhu, Y. Wang and Y. Zhang, "Formability and lubrication of a B-pillar in hot stamping with 6061 and 7075 aluminum alloy sheets," Procedia Engineering, vol. 207, pp. 723-728, 2017. DOI: https://doi.org/10.1016/j.proeng.2017.10.819.

[7] M. Kumar, N. Sotirov and C. Chimani, "Characterization of High Strength Al-Zn-Mg Alloy Sheet for Hot Stamping,” Materials Science Forum, 794-796, pp. 796-801, 2014. DOI: https://doi.org/10.4028/www.scientific.net/MSF.794-796.796.

[8] R. W. Hall, A. Foster and A. H. Praturlon, "Hot forming and quenching pilot process development for low cost and low environmental impact manufacturing," Journal of Physics: Conference Series, vol. 896, p. 12088, 2017. DOI: https://doi.org/10.1088/1742-6596/896/1/012088.

[9] X. Fan, Z. He, S. Yuan and P. Lin, "Investigation on strengthening of 6A02 aluminum alloy sheet in hot forming-quenching integrated process with warm forming-dies," Materials Science and Engineering: A, vol. 587, pp. 221-227, 2013. DOI: https://doi.org/10.1016/j.msea.2013.08.059.

[10] T. Grohmann, Forming of AMAG 7xxx Series Aluminium Sheet Alloys Stuttgart, 2016.

[11] E. Sáenz de Argandoña, L. Galdos, R. Ortubay, J. Mendiguren and X. Agirretxe, "Room Temperature Forming of AA7075 Aluminum Alloys: W-Temper Process," Key Engineering Materials, 651-653, pp. 199-204, 2015. DOI: https://doi.org/10.4028/www.scientific.net/KEM.651653.199.

[12] Yumi Choi, Jinwoo Lee, Sudhy S. Panicker, Hong-Kyo Jin, Sushanta Kumar Panda and MyoungGyu Lee, "Mechanical properties, springback, and formability of W-temper and peak aged 7075 aluminum alloy sheets: Experiments and modeling," International Journal of Mechanical Sciences, vol. 170, pp. 682-694, 2020. DOI: https://doi.org/10.1016/j.ijmecsci.2019.105344.

[13] J. M. Schlosser, S. Mouchtar, W. Rimkus and R. Schneider, Design optimisation of a side impact beam made out of high strength aluminium alloys using Barlat YLD2000 and GISSMO failure model for the "Extended Hotforming Process" Koblenz, 2019.

[14] German Institute for Standardisation, Metallic materials - Sheet and strip - Determination of forming-limit curves, vol. 77.040.10 (12004-1:2020) (Berlin: Beuth Verlag GmbH, 2021).

[15] B. Milkereit, M. Österreich, P. Schuster, G. Kirov, E. Mukeli and O. Kessler, "Dissolution and Precipitation Behavior for Hot Forming of 7021 and 7075 Aluminum Alloys," Metals, vol. 8, no. 7, p. 531, 2018. DOI: https://doi.org/10.3390/met8070531.

[16] J. M. P. Martins, J. L. Alves, D. M. Neto, M. C. Oliveira and L. F. Menezes, "Numerical analysis of different heating systems for warm sheet metal forming," The International Journal of Advanced Manufacturing Technology, vol. 83, 5-8, pp. 897-909, 2016. DOI: https://doi.org/10.1007/s00170015-7618-9.

[17] K. Zheng, Y. Li, S. Yang, K. Fu, J. Zheng, Z. He and S. Yuan, "Investigation and Modeling of the Preheating Effects on Precipitation and Hot Flow Behavior for Forming High Strength AA7075 at Elevated Temperatures," Journal of Manufacturing and Materials Processing, vol. 4, no. 3, p. 76, 2020. DOI: https://doi.org/10.3390/jmmp4030076.

[18] H. Dell, H. Gese and G. Oberhofer, "CrachFEM - A Comprehensive Approach For The Prediction Of Sheet Metal Failure,” in AIP Conference Proceedings: AIP, 2007, pp. 165-170. 